Global Sustainability

cambridge.org/sus

\section{Editorial}

Cite this article: Rockström J, Bai X, deVries B (2018). Global sustainability: the challenge ahead. Global Sustainability 1, e6, 1-3. https:// doi.org/10.1017/sus.2018.8

Received: 29 May 2018

Revised: 29 May 2018

Accepted: 29 May 2018

\section{Keywords:}

communication and education; policies; politics and governance

Author for correspondence:

J. Rockström, E-mail: johan.rockstrom@su.se

\title{
Global sustainability: the challenge ahead
}

\section{Johan Rockström ${ }^{1}$, Xuemei Bai ${ }^{2}$ and Bert deVries ${ }^{3}$}

${ }^{1}$ Stockholm Resilience Centre, Stockholm University, Sweden; ${ }^{2}$ Fenner School of Environment and Society, Australia National University, Australia and ${ }^{3}$ Copernicus Institute of Sustainable Development, Utrecht University, the Netherlands

\section{Our world and Earth in transition}

If one looks around in the world today, one realizes it has changed beyond recognition since the beginning of the Industrial Revolution in the late 18th and early 19th century. Neither King Louis XVI nor Voltaire, neither Watt nor Goethe could have imagined a world in which the human population has increased six fold, with a four hundred fold growth in Gross World Product (in international dollars), every sixth human being owns a transport means on four wheels, commercial airlines carry just over four billion passengers all over the planet, and approximately half of the world population is in near-continuous voice and face contact with the rest of the world.

Exponential growth of the human enterprise, resulting in an exponential growth in human pressures on the Earth system has led to a profound and potentially paradigm shifting scientific conclusion: humanity has entered a new geological Epoch, the Anthropocene. Since embarking on the great acceleration of the human enterprise in the mid-1950s (Steffen et al., 2015), we have transitioned from being a relatively 'small world on a big planet', to a relatively 'large world on a small planet'. Unleashed by the dynamic forces of science and technology and of industrial capitalism, people and the biophysical systems upon which they depend, have also become ever more connected and interdependent, in the globalized world of the Anthropocene.

At this juncture, where the aggregate forces of the human world directly influence the biophysical functioning of the Earth, there is an urgent need for sustainable development and, to guide it, science for global sustainability that transitions from focusing on one-problem-at-one-scale at a time, to truly exploring the complexity and systemic nature of the simultaneous and mutually interacting cause-and-effect chains in the interdependent human-nature and people-planet reality of the 21 st century.

Rising social-ecological turbulence and interactions show up across a variety of space and time scales: from local to global, from micro to macro, from very fast to very slow. Globalizing media, nanosecond financial transactions, corporate logistics and low transport costs accelerate trade flows and economic, social and political interdependencies and instabilities.

Demand for fossil-fuels continues to grow as the world economy expands, so far outpacing the exponential growth in renewable energy output. The Paris climate agreement, adopted by all nations in the world and which requires a transformation to a decarbonized world economy by 2050 , is necessary but not sufficient to attain global sustainable development. Mass migration into cities and towns, the result of complex social-ecological interactions, brings about new challenges and opportunities for human-nature relationships - a surge in traffic, poor housing and sanitation, and air and water pollution on the one hand, and better access to education, enhanced productivity due to scale effects and accelerated innovation on the other. Vulnerability and social fragility rises with increasing frequency of extreme droughts and floods, exacerbating conflict in areas where people live already under the stress of water and food scarcity. The growth in meat consumption drives increased deforestation, which is another cause of climate change and major loss in biodiversity - but to combat it with the replacement of oil by biofuels affects land use and food prices worldwide. Simple utopian blueprints will not work in the complex world of the 21 st century.

\section{The urgent need for global sustainability}

There is ever more evidence that in this largely unplanned and uncontrolled human experiment on Earth, humanity is at high risk of crossing one or more hard-wired Earth system thresholds with irreversible consequences. This may seriously affect the future potential for human well-being, which in turn requires serious rethinking and bolstering our research agenda towards plausible and desirable futures in the Anthropocene (Bai et al. 2016). The goal of sustainable development, as defined by the 'Our Common Future' report in 1987 (World Commission on Environment and Development, 1987) as "meeting the needs of the present without compromising the ability of future generations to meet their own needs" may get out of reach. We have now reached a juncture where it is imperative to 
construct new development narratives and paradigms, that guide us towards a world in which human needs and aspirations are met within the safe operating space of a stable and resilient Earth system (Rockström et al. 2009).

This evolution in thinking and recognition of the need for global sustainable development is clearly reflected in the transition from the 2002 Millennium Development Goals to the 2015 Sustainable Development Goals and the Paris Climate Agreement. For the first time, humanity has a world development roadmap, democratically agreed upon by all nations in the world, of attaining a socially inclusive and equitable world that meets human needs and aspirations within global environmental targets for a manageable Earth system. The need to integrate world development with Earth stability, is strongly supported in the 2018 Global Risk Report of the World Economic Forum (WEF, 2018), which turns interconnected risks on its head, for the first time placing failure on climate mitigation, water crises and biodiversity collapse highest in the ranking of global risks. As these directly interact with governance, economic growth and inter-state conflict, and surpass the perceived risks of terrorism, corruption and financial crises, global sustainability is truly a central human imperative. The relevance of interdisciplinary sustainability science as a knowledge frontier has risen tremendously over recent years. In short, the world expects answers to the grand challenge of how to transform the world to global sustainability on Earth.

The rising recognition that human development hinges on global sustainability, is transformative. Until recently, humanity has relied on a development logic in which societies evolve largely independently of one another and other biomes or Earth system processes, such as the climate system or moisture feedback from forests regulating downwind rainfall; each essentially pursuing social and economic development within the relatively stable environmental conditions of the Holocene. In the Anthropocene, this is changing. Humans are intensely interfering with, and are at all scales, dependent on Earth system processes, such as climate, oceans and forests. Local development anywhere in the world, from agro-pastoral communities on the African Savannah or reindeer herders in Siberia, to urbanites in Beijing or New York, is intertwined and interdependent in many ways with development elsewhere.

The rising call for an urgent transformation to global sustainability, so far largely voiced by the scientific community, is increasingly recognized by the policy and business communities in the world. The UN Sustainable Development Goals are one example, complemented by a myriad of initiatives, from the science-based targets initiative for climate in partnership with the We Mean Business network, to the sustainable cities initiative by the C40 network of major cities and the myriad of small-scale local community projects around the world. From all this emerges a grand scientific quest, to generate evidence and insights, of the necessity, possibilities and benefits of transforming societies and the world to global sustainability.

\section{The emerging field of science and scholarship on global sustainability}

The field of sustainability science, fully emerging around the turn of the Millennium (Kates et al., 2001; deVries, 2013), sets out to understand the fundamental character of interactions between nature and society. It has become a flourishing field of research, with over three million hits in Google Scholar, new schools and programs emerging around the world, and several new scientific journals dedicated to it. Much theoretical exploration and empirical evidence has accumulated across the world. For example, one of the core questions identified by Kates et al. (2001) was "Can scientifically meaningful 'limits' or 'boundaries' be defined that would provide effective warning of conditions beyond which the nature-society systems incur a significantly increased risk of serious degradation?" Some powerful concepts such as the Anthropocene and planetary boundaries that emerged and gained popularity in scientific literature and policy arena have effectively responded to this question and advanced this frontier.

However, much remains to be done. We know that the various interactions between nature and society are interconnected, driven by various complex dynamics and interactions, with surprise and unintended consequences across scales. We have only started to scratch the surface of how such interconnections and consequences play out at multiple scales, across issue domains and at a system level.

Science and scholarship on global sustainability widens the interdisciplinary scope further, by adding the insights of the Anthropocene, that is, the interdependence of humanity and society, the world and the Earth, into an integrated people-planet research agenda, seeking insights and solutions to key questions and challenges such as:

- How do social and natural systems interact, from local to global scales, in the form of supply-demand chains, behavioural change and nested lock-in dynamics, and tele-couplings?

Which implications do these interactions have on (the potential for) human well-being and development, as well as to the Earth system?

- What are the social transformations across scales, cultures and sectors that can enable human development pathways towards a world that evolves within the safe operating space on Earth?

To enable a deeper understanding of world-Earth interactions in the Anthropocene, science for global sustainability advances key scientific concepts and definitions, theories, methods and tools in:

- Understanding the dynamics and cross-scale interactions of evolving, coupled social-ecological systems (SES) in the Anthropocene;

- Advancing theory and methods for integration of social and natural sciences that include temporal and spatial interactions;

- Is a problem-driven research field, exploring ways to manage complex and coupled social-ecological systems for human wellbeing and Earth system resilience;

- Advances transdisciplinary methods and inquiries, that is, engaging scholars from different disciplines (interdisciplinary) and stakeholders outside of academia, recognizing that solutions to sustainability problems need to be embedded in societies, and adapted to a world of rising integration, complexity and uncertainty;

- Focuses on interactions between resource systems (Earth/life sciences), its users (equity and rights) and governance systems across scales.

\section{The challenge of integration}

Sustainability science is by nature interdisciplinary. Integrating natural and social sciences in an Anthropocene inquiry of 
pathways to sustainable development, may sound straight forward, but is nothing less than a scientific revolution.

Disciplinary science is, and will continue to be, fundamental for the advancement of knowledge, and a key for collaborative, problem-oriented interdisciplinary inquiries in science for global sustainability. However, scientific disciplines, across social and natural sciences, are embedded in different perspectives, conceptual and theoretical framings. This is one of the obstacles to be overcome in research across disciplines. Besides, disciplinary research is usually not free from underlying value systems and worldviews. Although this too, particularly in the social sciences, may hamper truly integrative approaches, we strongly argue that such a plurality in understanding world-Earth interactions is healthy and needed in the pursuit of global sustainability. Indeed, such integrated approaches are urgently needed if we are to find solutions for global sustainability in a heavily intertwined world-Earth system.

Advancements in integrated theories and methods are crucial. At the same time it is key to recognize, with academic humility, the challenge it entails, and that new insights in social science embedded in state-of-the-art Earth system science, and in natural science embedded in state-of-the-art social science of the globalized world of the 21 st century, are crucial contributions to sustainability science.

Furthermore, sustainability science needs to connect the scientific research to the political agenda. Such a connection has been a core aspiration of sustainability science from the very beginning. There is a growing scientific literature on trans-disciplinary research (Lang et al. 2012; Miller et al. 2014), and an increasing emphasis on co-design and co-production between research, policy and practitioner communities, and an increasing emphasis on solutions-oriented research.

\section{Global Sustainability: the journal}

It is against this background that the new journal Global Sustainability has been launched by Cambridge University Press. The journal aims to explore interactions between social and natural systems, from local to global scales, with a particular focus on transformations towards sustainability as an avenue for human development within planetary boundaries.

We adopt a wide definition of interdisciplinary science for global sustainability. As shown in the Scope of the Journal, and reflected in the breadth of the disciplinary expertise in the Editorial Board of the Journal, we invite research anchored in different disciplines, from geology to psychology, with the core ambitions of encouraging advances in social and natural sciences set in the context of Earth system science, global environmental change, global governance and planetary stewardship.

Added to this, we are excited about the emerging trend towards sustainability science as an interdisciplinary academic field in its own right, and encourage contributions advancing thinking and frameworks that go beyond academic disciplinary lines.

We see integration as one of the objectives of the new journal, bringing different viewpoints and the associated concepts, theories and methods together. We encourage trans-disciplinary approaches in which qualitative concepts and stories are creatively combined with quantitative models and methods.

We are particularly interested in inter- and trans-disciplinary research articles, intelligence briefs and commentaries, that connect scales from local ecosystems and communities to global trends in environmental and socio-economic variables, and in scientific attempts to draw generic insights and solutions from case studies on sustainable development in different parts of the world.

Global Sustainability welcomes place based case studies at different scales, as these are empirical pillars of sustainability science. The case studies submitted should strive to go beyond reporting the empirical findings from the case. This can include the introduction of conceptual and theoretical contributions to sustainability science; the exploration of cross-scale, cross-sector and cross-disciplinary interactions, impacts and implications; and proposals to transfer of learnings and implications to other contexts within the same scale and to demonstrate the global impacts of collective actions.

In summary, we welcome conceptual and theoretic papers as well as empirical and applied studies. The key is that all research presented in Global Sustainability is set in the context of humanity's new reality as a 'big world on a small planet'.

In this way, the Journal hopes to encourage and contribute to new insights into pathways towards a sustainable future for humanity on Earth.

Author contributions. J. R., X. B. and B. D. wrote the article.

Financial support. None.

\section{References}

Bai, X., Van Der Leeuw, S., O’Brien, K., Berkhout, F., Biermann, F., Brondizio, E.S., Cudennec, C., Dearing, J., Duraiappah, A., Glaser, M., \& Revkin, A. (2016). Plausible and desirable futures in the Anthropocene: a new research agenda. Global Environmental Change, 39, 351-362.

deVries, B. (2013). Sustainability Science. Cambridge University Press

Kates, R., Clark, W.C., Corell, R., Hall, J.M., Jaeger, C.C., Lowe, I., McCarthy, J.J., Schellnhuber, H.J., Bolin, B., Dickson, N.M., Faucheux, S., Gallopin, G.C., Grübler, A., Huntley, B., Jäger, J., Jodha, N.S., Kasperson, R.E., Mabogunje, A., Matson, P., Mooney, H., Moore 3rd, B., O'Riordan, T., \& Svedlin, U. (2001). Sustainability Science. Science, 292 (5517), 641-642.

Lang, D.J., Wiek, A., Bergmann, M., Stauffacher, M., Martens, P., Moll, P., Swilling, M., \& Thomas, C.J. (2012). Transdisciplinary research in sustainability science: practice, principles, and challenges. Sustainability Science, 7 (1), 25-43.

Miller, T.R., Wiek, A., Sarewitz, D., Robinson, J., Olsson, L., Kriebel, D., \& Loorbach, D. (2014). The future of sustainability science: a solutions-oriented research agenda. Sustainability Science, 9(2), 239-246.

Rockström, J., Steffen, W., Noone, K., Persson, Å., Chapin III, F.S., Lambin, E.F., Lenton, T.M., Scheffer, M., Folke, C., Schellnhuber, H.J., \& Nykvist, B. (2009). A safe operating space for humanity. Nature, 461 (7263), 472.

Steffen, W., Broadgate, W., Deutsch, L., Gaffney, O., \& Ludwig, C. (2015). The trajectory of the Anthropocene: The Great Acceleration. The Anthropocene Review, 2(1), 81-98.

WEF (2018). The Global Risks Report 2018, 13th Edition. World Economic Forum, Geneva. Retrieved from http://wef.ch/risks2018

World Commission on Environment and Development (1987). Our Common Future. Oxford University Press, Oxford, UK. 